\title{
Ludwig's Angina: a study of 50 cases
}

\author{
Md. Abu Yusuf Fakir ${ }^{1}$, Md. Arif Hossain Bhuyan², Md. Mosleh Uddin ${ }^{3}$ HM Mustafizur Rahman ${ }^{4}$, Syed \\ Hasan Imam Al-Masum ${ }^{5}$, A.F. Mohiuddin Khan ${ }^{6}$
}

\begin{abstract}
Objective: To evaluate the clinical outcome, morbidity and mortality of patients diagnosed as Ludwig's angina. Study design: Retrospective study.

Setting: Department of Otolaryngology \& Head and Neck Surgery, Dhaka Medical College Hospital and Apollo Hospitals Dhaka.

Patients and Methods: 50 patients were included in this study (36 males and 14 female) between the ages of 8 and 78 years (mean, 45.5 years) who were treated between January 2007 and December 2008 in the department of Otolaryngology and Head-Neck surgery, Dhaka Medical College Hospital and Apollo Hospitals Dhaka. Etiology, microbiology, associated systemic diseases, treatment, airway management, duration of hospital stay and outcome were reviewed.

Results: Most common age group was $3^{\text {rd }}$ decade (42\%) and $72 \%$ patients were male. Most patients came from poor socio-economic condition and rural area of Bangladesh. $100 \%$ patients presented with neck swelling, pain, tenderness and fever. Dental infection was documented as the most common cause (70\%) of Ludwig's angina, followed by infection of the tonsils (10\%) and submandibular gland (6\%). Systemic illnesses included diabetes mellitus (30\%) and chronic renal failure (4\%). Streptococcus is commonest organism found in culture of pus. Intravenous antibiotics were started immediately in all patients. 4 patients underwent emergency tracheostomy. 40 patients underwent incision and drainage. Infected tooth/ teeth were also removed at the same time. Postoperatively, the airway was secured by endotracheal intubation in 1 case and by tracheotomy in 5 cases. In $88 \%$ ( 44 patients) of the cases, no artificial airway was used. 9 patients were managed in the intensive care unit for 1 to 3 days. All except 1 patient made uneventful recoveries and they were discharged after 3 to 26 days of hospitalization (mean, 14.1 days).
\end{abstract}

Conclusion: Airway protection, aggressive antibiotic therapy and surgical decompression can significantly alter the mortality rate of Ludwig's angina.

Key Words: Cellulitis, Ludwig's angina, surgical decompression

1. Registrar, Dept. of Otolaryngology and Head- Neck Surgery, Dhaka Medical College Hospital, Dhaka.

2. Senior Registrar, Dept. of Otolaryngology and HeadNeck Surgery, Apollo Hospitals Dhaka.

3. Assistant Professor, Dept of Otolaryngology, BSMMU, Dhaka.

4. Assistant Professor, Dept. of Otolaryngology and Head- Neck Surgery, Enam Medical College and Hospital, Dhaka.

5. Consultant, Dept. of Otolaryngology and Head- Neck Surgery, Dhaka Shishu Hospital.

6. Associate Professor, Dept. of Otolaryngology and Head- Neck Surgery, Dhaka Medical College Hospital, Dhaka.

Address of correspondence : Dr. Md. Abu Yusuf Fakir, Registrar, Dept. of Otolaryngology and HeadNeck Surgery, Dhaka Medical College Hospital, Dhaka

\section{Introduction}

Ludwig's angina is an infection of the submandibular region, manifested by swelling of the floor of the mouth and elevation and posterior displacement of the tongue. A brawny edema and cellulitis of the suprahyoid region of the neck develops later ${ }^{1}$. Deep neck abscesses such as Ludwigs angina are less common now than 50 years ago because of the development of effective antibiotics and improved dental care. Deep neck infections in the antibiotic era most commonly result from odontogenic infections ${ }^{2}$. The most common predisposing factors for the development of Ludwig's angina are carious and abscessed teeth, periodontal disease and extractions of the lower molars. Uncommon etiologies include upper respiratory infections, floor-of-mouth trauma, mandibular fractures, 
peritonsillar abscess and sialadenitis ${ }^{3}$. The second and third mandibular molars have roots which lie at the level of the mylohyoid muscle, either adjacent to or below the submandibular space. Abscesses of these lower molars may perforate the mandible and spread into the submandibular and submental spaces, leading to Ludwig's angina. The causative organisms are generally those of the oral flora, including: Streptococcus spp., Staphylococcus aureus ,Bacteroides spp.,Fusobacterium spp., Actinomyces spp. and Haemophilus influenzae ${ }^{4}$. All age groups may be affected, but young adults have the highest prevalence rates ${ }^{5}$. The disease is unusual in children. The infection begins unilaterally ${ }^{6}$. Swelling of the tissues occurs rapidly and may block the airway or prevent swallowing of saliva.

Symptoms include:

- Breathing difficulty

- Confusion or other mental changes

- Fever

- Neck pain

- Neck swelling

- Redness of the neck

- Weakness, fatigue, excessive tiredness

- Earache

- Drooling of saliva

- Foul smell

The patency of the airway is the main concern with Ludwig's angina and patients may require a tracheostomy to prevent airway obstruction. Infections of the submandibular space may spread to the lateral pharyngeal and retropharyngeal spaces. From the retropharyngeal space, the infection can dissect down fascial planes to the mediastinum. Aspiration of infectious particles and septic embolism to the pulmonary vasculature is other possible modes of extension to the chest ${ }^{7}$.A CT scan of the neck may be recommended. Plain radiographs can be used to assess the degree of soft tissue swelling and airway obstruction ${ }^{8}$. Culture of fluid from the tissues may show bacteria. Ludwig's angina can be life threatening. However, it can be cured with proper protection of the airways and appropriate antibiotics.

\section{Patients \& Methods}

This study included fifty patients of Ludwig's Angina that were treated medically and surgically in the department of Otolaryngology and Head-Neck Surgery at Dhaka medical College hospital and Apollo Hospitals Dhaka from January, 2007 to December 2008. The data of each patient included age, sex, socio-economic status, etiology, microbiology, airway management, presenting symptoms and signs, preoperative investigations like complete blood count, blood sugar, serum creatinine etc., operation notes, complications of surgery and state at follow up.

\section{Result}

The observation of study shown in following tables.

Table-I

Age of patients $n=50$

\begin{tabular}{lcc}
\hline Age of the patient & $\begin{array}{c}\text { Number of } \\
\text { patients }\end{array}$ & $\begin{array}{c}\text { Percentage } \\
(\%)\end{array}$ \\
\hline $1^{\text {ST }}$ Decade & 3 & 6 \\
$2^{\text {nd }}$ Decade & 2 & 4 \\
$3^{\mathrm{RD}}$ Decade & 21 & 42 \\
$4^{\mathrm{TH}}$ Decade & 8 & 16 \\
$5^{\mathrm{TH}}$ Decade & 11 & 22 \\
$6^{\mathrm{TH}}$ Decade & 3 & 6 \\
$7^{\mathrm{TH}}$ Decade & 2 & 4 \\
\hline
\end{tabular}

Most Common Age group was $3^{\text {rd }}$ decade (42\%) followed by $5^{\text {th }}$ and $4^{\text {th }}$ decade.

Table-II

Sex distribution of patients $n=50$

\begin{tabular}{lcc}
\hline Sex of Patients & No of patients & $\%$ \\
\hline Male & 36 & 72 \\
Female & 14 & 28 \\
\hline
\end{tabular}

Table-II shows $72 \%$ patients were male and $28 \%$ were female.

Table-III

Socio-economic conditions $n=50$

\begin{tabular}{lcc}
\hline Socio-economic status & No of patients & $\%$ \\
\hline Poor & 35 & 70 \\
Middle & 10 & 20 \\
Affluent & 5 & 10 \\
\hline
\end{tabular}

Most common cases were poor socio- economic condition (70\%). 
Table-IV

Type of dwelling $n=50$

\begin{tabular}{lcc}
\hline Inhabitant & No of Patients & $\%$ \\
\hline Rural & 41 & 82 \\
Urban & 9 & 18 \\
\hline
\end{tabular}

Most of patients came from rural area of Bangladesh (82\%)

Table-V

Common Symptoms of patients $n=50$

\begin{tabular}{lcc}
\hline Symptoms & No of Patients & Percentage \\
\hline Neck Swelling & 50 & 100 \\
Pain and tenderness & 50 & 100 \\
Fever & 50 & 100 \\
Dysphagia & 40 & 80 \\
Dental problem & 35 & 70 \\
Foul smell & 12 & 24 \\
Trismus & 7 & 14 \\
Muffled Voice & 10 & 20 \\
Respiratory distress & 4 & 8 \\
\hline
\end{tabular}

Most common symptoms were neck swelling, pain, tenderness and fever. (In all patients). More than one symptom was present in all patients.

Table-VI

Etiological factor $n=50$

\begin{tabular}{lcc}
\hline Etiology & No of Patients & Percentage \\
\hline Dental problem & 35 & 70 \\
Diabetes Mellitus & 15 & 30 \\
Tonsillar infection & 5 & 10 \\
Infection in oral mucosa & 3 & 6 \\
Submandibular infection & 3 & 6 \\
Chronic renal failure & 2 & 4 \\
\hline
\end{tabular}

35 patients $(70 \%)$ presented with dental problems followed by diabetes mellitus (30\%) and tonsillar infections (10\%). 10 patients of diabetes mellitus had associated dental infection. Isolated diabetes mellitus has been found in 5 cases.
Table-VII

Microbiology $n=32$

\begin{tabular}{lcc}
\hline Organism & No of Patients & Percentage \\
\hline Streptococcus & 13 & 40.62 \\
Stapylococcus & 6 & 18.75 \\
E.coli & 4 & 12.5 \\
Psedomonus & 3 & 9.37 \\
Proteus & 2 & 6.25 \\
Klebsiella & 1 & 3.125 \\
No organisms & 3 & 9.37 \\
\hline
\end{tabular}

In 32 patients pus has been sent for culture and sensitivity. Maximum organisms found were Streptococcus (40.62\%) followed by staphylococcus (18.75\%) and E.Coli (12.5\%).

Table-VIII

Nutritional Status $n=50$

\begin{tabular}{lcc}
\hline Nutritional Status & No of Patients & Percentage \\
\hline Average & 10 & 20 \\
Under nutrition & 40 & 80 \\
\hline
\end{tabular}

40 patients (80\%) presented with Ludwig's angina were under nutrition.

Table-IX

Complications $n=50$

\begin{tabular}{lcc}
\hline Complications & No of Patients & Percentage \\
\hline Necrotizing Fascitis & 4 & 8 \\
Septicaemia & 4 & 8 \\
Mediastinitis & 3 & 6 \\
Laryngeal Edema & 1 & 2 \\
Death & 1 & 2 \\
\hline
\end{tabular}

Maximum complications were necrotizing fascitis(8\%) and septicaemia(8\%) followed by mediastinitis(6\%).

Table-X

Hospital stay

\begin{tabular}{lcc}
\hline Hospital stay & No of Patients & Percentage \\
\hline Up to 1 week & 6 & 12 \\
1-2 weeks & 18 & 36 \\
2-3 weeks & 7 & 14 \\
3-4 weeks & 6 & 12 \\
$>$ 4 weeks & 6 & 12 \\
\hline
\end{tabular}


Maximum hospital stay was between 1-2 weeks in 18 patients (36\%). They were discharged after 3 to 26 days of hospitalization (mean, 14.1 days).

Table-XI

Treatment

\begin{tabular}{lcc}
\hline Treatment & No of patients & Percentage \\
\hline Conservative & 10 & 20 \\
Incision and Drainage & 40 & 80 \\
\hline
\end{tabular}

40 patients (80\%) underwent incision and drainage. $10(20 \%)$ patients have been cured with conservative measure.

All but 1 patient made uneventful recoveries.One patient died due to mediastinitis on 4th day after admission.

CT neck has been done for 8 patients and X-ray neck has been done for 25 patients.

\section{Discussion}

Ludwig's angina was first described by the German physician Wilhelm Friedrich von Ludwig in 1836. At that time, the condition was almost always fatal. ${ }^{9}$ With the advent of contrast-enhanced CT, which has allowed earlier identification and prompt antibiotic therapy, the mortality rate has significantly declined, from more than $50 \%$ to less than $10 \%$ of patients. ${ }^{10,11}$ In our study 1 patient(4\%) died of mediastinitis.

Our study shows that male are affected more than female and it mainly affects in poor socio-economic conditions. In our study, $72 \%$ patients were male and most patients were from poor socio economic condition (70\%) and from rural area of Bangladesh (82\%). 40 patients (80\%) presented with Ludwig's angina were under nutrition.

Ludwig's angina is a rapidly spreading, indurated, bilateral cellulitis that begins in the floor of the mouth and involves both the submandibular and sublingual spaces. ${ }^{12}$ It spreads along fascial planes rather than by lymphatics and rarely involves the glandular surfaces. ${ }^{13}$

The primary site of infection is odontogenic in $70 \%$ to $80 \%$ of cases. ${ }^{14}$ In our series, 35 patients (70\%) presented with dental problems followed by diabetes mellitus (30\%) and tonsillar infections (10\%). 3 patients presented with infection of oral mucosa and 3 patients presented with submandibular adenitis. The second and third molars are most frequently involved, because their roots extend below the level of the mylohyoid muscle, thus crossing both the sublingual and submandibular spaces. ${ }^{15}$ The majority of the patients are adults who have no significant comorbidities. In our study, most common age group was $3^{\text {rd }}$ decade $(42 \%)$ followed by $5^{\text {th }}$ and $4^{\text {th }}$ decade. This condition has also been associated with systemic diseases, such as chronic glomerulonephritis, systemic lupus erythematosus, aplastic anemia, neutropenia, immunodeficiency (eg, HIV infection) and diabetes mellitus. ${ }^{16}$

The bacteriology of Ludwig's angina is polymicrobial. The most common organisms identified include Streptococcus, Staphylococcus and Bacteroides species. Other microorganisms that have been isolated are gram-negative bacteria, such as Klebsiella species, Hemophilus influenzae, Proteus species, and $\mathrm{P}$ aeruginosa. ${ }^{17}$ In our study 32 patients pus has been sent for culture and sensitivity. Maximum organisms found were Streptococcus (40.62\%) followed by staphylococcus and E.Coli.

Pain in the floor of the mouth and anterior neck, dysphagia, odynophagia and respiratory distress are common symptoms. ${ }^{18}$ Clinical findings include fever, tachypnea and tachycardia and patients may also have fetid breath. Stridor, hoarseness, respiratory distress, cyanosis and decreased air movement are harbingers of impending upper airway compromise.

Palpation of the submental and bilateral submaxillary spaces reveals firm, nonpitting induration of the suprahyoid neck bilaterally. Inspection of the malodorous oral cavity is limited because of trismus, but a firm, raised floor of the mouth may be evident. ${ }^{18}$ In our study, most common symptoms were neck swelling, pain, tenderness and fever. (In all patients). Other presenting symptoms were dysphagia, dental problem, foul smell, trismus, muffled voice and respiratory distress. More than one symptom was present in all patients.

Maximum hospital stay was between 1-2 weeks. They were discharged after 3 to 26 days of hospitalization (mean, 14.1 days).

Although abscess formation is not always associated with Ludwig's angina, some cases will eventually evolve into an abscess. Complications of Ludwig's angina include sepsis, pneumonia, asphyxia, empy-ema, pericarditis, mediastinitis and 
pneumothorax. ${ }^{18}$ In our study, maximum complications were nectrotizing fascitis(8\%) and septicaemia(8\%) followed by mediastinitis(6\%).1(2\%) patient developed laryngeal odema and has been treated with IV antibiotics and steroid(non-diabetic) with favorable outcome.

Diagnosis is based on clinical findings, although contrast-enhanced CT can help determine the extent of the infection, especially in the presence of an abscess. ${ }^{19} \mathrm{Clinical}$ examination has a low sensitivity (55\%) for predicting drainable collections of pus in deep neck infections, but when combined with CT findings, the accuracy is $89 \%$, sensitivity is $95 \%$, and specificity is $80 \%$ for identifying a drainable collection. ${ }^{20}$ Plain radiographs of the neck may show soft-tissue swelling, the presence of gas and the extent of airway narrowing. In our study, CT neck has been done for 4 cases and X-ray neck has been done for 25 patients. Although CT neck is an excellent guide to assess the extension of the disease, most of our patient could afford to do the same. 9 patients were managed in the intensive care unit for 1 to 3 days.

Because of the risk of rapid airway compromise, all patients with Ludwig's angina should be admitted to the ICU. Again that was not always possible for us as we have few ICU facility. Death is usually the result of hypoxia or asphyxia, not overwhelming sepsis, ${ }^{12}$ although mediastinitis was the likely cause in our patient. Airway management is the most important aspect of immediate care. Tracheostomy using local anesthesia has been considered the gold standard of airway management in patients with deep-neck infections. However, cellulitis of the neck with involvement of the tracheostomy site makes the procedure difficult. ${ }^{20}$ In our study, 5 patients underwent tracheostomy. A recent study included 17 patients with Ludwig's angina showed that tracheal intubation with a flexible bronchoscope using topical anesthesia provided good airway management. The authors recommended tracheostomy using local anesthesia when fiberoptic intubation is not possible. ${ }^{20}$

Initial antibiotic therapy is targeted at gram-positive organisms and oral cavity anaerobes. Empiric therapy with IV penicillin G, clindamycin or metro-nidazole is recommended before culture report is available. ${ }^{20}$ Some experts recommend the addition of gentamicin. ${ }^{21}$ Antibiotic treatment before hospital admission often results in sterile cultures. IV steroids given for 48 hours, can decrease edema and cellulitis and thus help maintain the integrity of the airway and enhance antibiotic penetration. We used IV steroid in 6 cases in non-diabetic patients. If an abscess is present, the definitive treatment would be incision and drainage and if applicable, removal of the abscessed tooth or teeth. We used combination of Inj Ceftrizone and Inj Metronidazole in all patients. Inj Gentamycin has been used additionally in 5 patients.

Surgical drainage is indicated in the presence of clinical fluctuance or crepitus or radiologic evidence of fluid collection or air in the soft tissues. A relative indication is the lack of clinical improvement within 24 hours of initiation of antibiotic therapy. ${ }^{21}$ Removal of infected teeth facilitates the complete drainage of fluid. In our study, 40 patients (80\%) underwent incision and drainage. $10(20 \%)$ patients have been cured with conservative measure.

\section{Conclusion}

Ludwig's angina usually resolves without complications, but the condition can be fatal. Prompt diagnosis, appropriate airway management, aggressive IV antibiotic therapy, incision and drainage and close monitoring promote good outcomes in most patients.

\section{References}

1. Har-El, Aroesty, Shaha and Lucente. Changing Trends in Deep Neck Abscesses, Oral Surgery Oral Medicine Oral Pathology, 1994; 77 (5): 446-50.

2. Fritsch and Klein. Curriculum in Critical Care: Ludwig's Angina, Heart \& Lung, 1992: 21: 39-47.

3. Cummings, Fredrickson, Harker, Krause and Schuller. Otolaryngology - Head and Neck Surgery, Second Ed, 1993; 2: 1199-1215.

4. Grodinsky. Ludwig's Angina: An Anatomical and Clinical Study with Review of the Literature, Surgery, 1939; 5: 678-96.

5. Shockley WW. Ludwig angina: a review of current airway management. Arch Otolaryngology Head Neck Surg, May 1999;125 (5): 600-604.

6. ScottA, Stiernberg N, Driscroll. Deep Neck Space Infections. Bailey Head \& Neck SurgeryOtolaryngology. 1998, Lippincot-Raven Cap. 58: 819-35. 
7. Lee, Tami, Echavez, and Wildes. Deep Neck Infections in Patients at Risk for Acquired Immunodeficiency Syndrome, Laryngoscope, Sep. 1990; 915-919.

8. Mendelson, Gurtman, Szabo et al. Pseudomonas aeruginosa Bacteremia in Patients with AIDS. Clinical Infectious Disease, 1994; 18: 886-95.

9. Hartmann RW Jr. Ludwig's angina in children. Am Fam Physician. 1999; 60:109-112.

10. Furst IM, Ersil P, Caminiti M. A rare complication of tooth abscess-Ludwig's angina and mediastinitis. J Can Dent Assoc, 2001; 67: 324327.

11. Kurien M, Mathew J, Job A, et al. Ludwig's angina. Clin Otolaryngol Allied Sci, 1997; 22: 263-265.

12. Srirompotong $S$, Art-Smart T. Ludwig's angina: a clinical review. Eur Arch Otorhinolaryngol. 2003; 260:401-403.

13. Sykora J, Varvarovska J, Stozicky F, et al. Adolescent herpes simplex viral infection related Ludwig's angina in ulcerative colitis. J Pediatr Gastroenterol Nutr, 2004; 38:221-223.

14. Hamza NS, Farrel J, Strauss M, et al. Deep fascial space infection of the neck: a continuing challenge. South Med J, 2003; 96:928-932.
15. Smith LM, Osborne RF. Infections of the head and neck. Top Emerg Med. 2003; 25: 106-116.

16. Jimenez Y, Bagán JV, Murillo J, et al. Odontogenic infections. Complications. Systemic manifestations. Med Oral Patol Oral Cir Bucal. 2004; 9 (suppl): 143-147.

17. Bansal A, Miskoff J, Lis RJ. Otolaryngologic critical care. Crit Care Clin, 2003;19: 55-72.

18. Ovassapian A, Tuncbilek M, Weitzel EK, et al. Airway management in adult patients with deep neck infections: a case series and review of the literature. Anesth Analg, 2005;100:585-589.

19. Miller WD, Furst IM, Sandor GK, et al. A prospective, blinded comparison of clinical examination and computed tomography in deep neck infections. Laryngoscope, 1999; 109:18731879.

20. Mehrotra M, Mehrotra S. Decompression of Ludwig angina under cervical block. Anesthesiology, 2002; 97: 1625-1626.

21. Ramadan $\mathrm{HH}$, El Solh AA. An update on otolaryngology in critical care. Am J Respir Crit Care Med., 2004; 169:1273-1277. 